\title{
Improving predictive modelling of coastal protection by salt marshes
}

\author{
Thomas J. van Veelen, Swansea University, t.j.van-veelen.922560@swansea.ac.uk \\ Harshinie Karunarathna, Swansea University, h.u.karunarathna@swansea.ac.uk \\ Tom P. Fairchild, Swansea University, t.fairchild@swansea.ac.uk \\ William G. Bennett, Swansea University, w.g.bennett@swansea.ac.uk \\ John Griffin, Swansea University, j.n.griffin@swansea.ac.uk \\ Dominic E. Reeve, Swansea University, d.e.reeve@swansea.ac.uk
}

\section{INTRODUCTION}

Salt marshes are vegetated tidal wetlands, which can typically be found at sheltered coastal areas in moderate climate zones. Their potential as natural coastal protection by wave attenuation (Möller et al, 2014), reduction of flood-surge propagation (Stark et al., 2016) and shoreline stabilization (Bouma et al, 2014) has been increasingly recognized among scientists and engineers, but it comes with risks.

Our understanding of the biogeomorphological dynamics between salt marsh vegetation, hydrodynamics and sediment is limited, while these are essential to identify the protective value of marshes to coastal protection (Wu et al., 2017). In this study, we present a predictive process-based model with a newly validated vegetation module to study the potential of salt marshes to contribute to coastal protection for a case study site in West Wales, United Kingdom.

\section{STUDY AREA}

The historic village Laugharne fully relies on salt marshes for its protection against storm surges. It is located on the shores of the macro-tidal Taf estuary in Southwest Wales, which is still relatively undisturbed (Fig. 1). The marsh platforms exhibit a mix of woody Halimione and flexible grass species, such as Puccinellia, Spartina and Juncus.

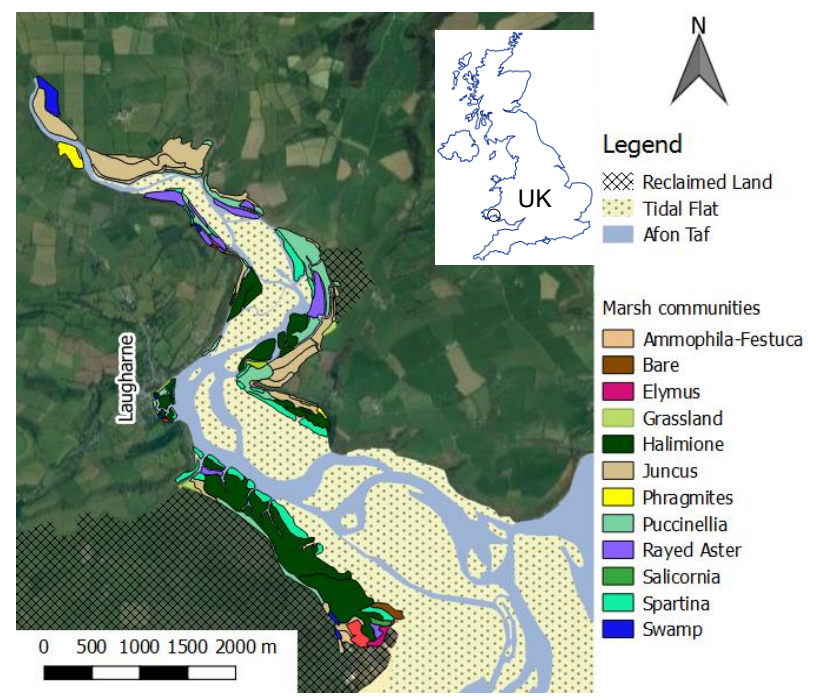

Figure 1 - Map of the Taf estuary, West Wales, UK.

\section{METHODS}

A high-resolution Delft3D (Lesser et al., 2004) numerical model is set up to allow for a scale and resolution required for this study; see Fig. 2 for the morphodynamic model domain. Besides, the flexibility in forcing and processes suits our focus on bio-geomorphological interactions. The standard morphodynamic modelling suite is coupled with an improved vegetation module to overcome the sensitivity of numerical models to plant representations, as noted by Tempest et al. (2015). It explicitly accounts for drag, turbulence and diffusion over the whole water column. Novelties include a parameterization for plant flexibility and exertion of hydrodynamic feedback on vegetation.

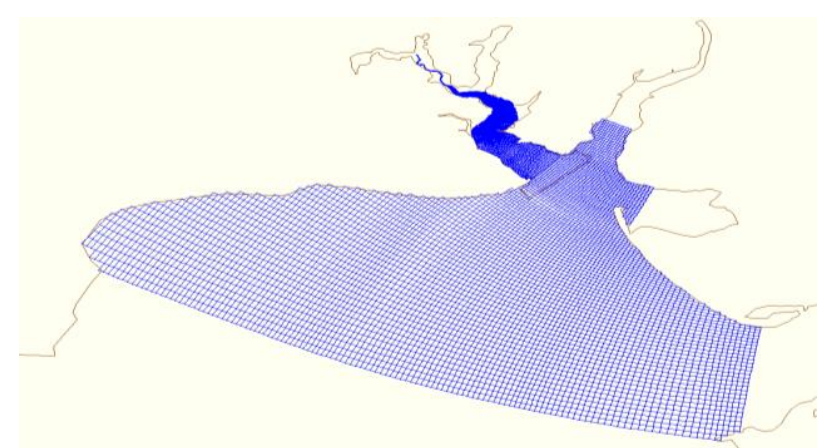

Figure 2 - The morphodynamic model domain.

Furthermore, this study benefits from data obtained during an extensive field campaign in the Taf estuary. This resulted in detailed topography, salt marsh communities and a dataset of mechanical plant properties, which were used to validate the model and its vegetation module. Also, flow velocities have been measured to validate the model.

The model is then used to simulate flooding of the case study site under calm weather and storm conditions. The calm weather conditions provide insight in interactions related to marsh accretion and the storm conditions show the direct contribution of the salt marsh to coastal flood protection.

\section{RESULTS}

A novel predictive process-based model has been applied to identify interactions between salt marsh vegetation, hydrodynamics and sediment transport that contribute to coastal protection services provided by salt marshes. In particular, we explicitly account for the three-dimensional hydrodynamics through and over flexible vegetation. The flow velocities show good agreement with field measurements.

Calm weather modelling highlights the effects of the salt marsh vegetation on estuarine hydro- and morphodynamics. It is shown how flow velocities are modified and how this relates to vegetation properties such as height density and flexibility as well as estuarine properties such as inlet size and area.

Storm modelling over a wide range of conditions shows that salt marshes in the Taf estuary contribute to wave attenuation and a reduction in flood water levels. Furthermore, a decrease of the flooded area in Laugharne 
town is observed due to the presence of salt marshes in the Taf estuary.

\section{REFERENCES}

Bouma et al. (2014): Identifying knowledge gaps hampering application of intertidal habitats in coastal protection: Opportunities \& steps to take, Coast. Eng., vol. 87, pp. 147-157.

Möller et al. (2014): Wave attenuation over coastal salt marshes under storm surge conditions, Nat. Geosci., vol. 7, pp. 727-731.

Lesser et al. (2004): Development and validation of a three-dimensional morphological model, Coast. Eng., vol. 51, pp. 883-915.

Stark et al. (2016): Coastal flood protection by a combined nature-based and engineering approach: Modeling the effects of marsh geometry and surrounding dikes, Estuar. Coast. Shelf S., vol. 175, pp. 34-45.

Tempest, Möller, Spencer (2015): A review of plant-flow interactions on salt marshes: the importance of vegetation structure and plant mechanical characteristics, WIREs Water, vol. 2, pp. 669-681.

Wu et al. (2017): Subgrid modeling of salt marsh hydrodynamics with effects of vegetation and vegetation zonation, Earth Surf. Proc. Land., vol. 42, pp. 1755-1768. 